\title{
Conhecimentos mobilizados por professores ao planejarem aulas sobre equações ${ }^{1}$
}

\author{
Alessandro Jacques Ribeiro ${ }^{2}$ \\ Felipe Augusto Pereira Vasconcelos Santos e Oliveira ${ }^{3}$
}

\begin{abstract}
Resumo: Fundamentado em resultados de pesquisas sobre a formação do professor, este estudo tem por objetivo investigar e mapear conhecimentos matemáticos de professores quando eles pensam e preparam aulas sobre equação. Tomamos por referencial teórico os estudos de Ball e colaboradores, em especial, as noções de "conhecimento do conteúdo e dos estudantes" e "conhecimento do conteúdo e do ensino". Do ponto de vista metodológico, trata-se de uma pesquisa qualitativa-interpretativa envolvendo um grupo de seis professores. Dentre os resultados, foram identificados elementos do "conhecimento de equação e dos estudantes", tais como: a dificuldade de os estudantes caracterizarem o conceito de equação, além de elementos do "conhecimento de equação e do ensino", como a valorização do contexto no momento de se preparar atividades de ensino sobre equação. Este estudo ratifica a relevância de se investigar professores envolvidos em sua própria prática, em especial, no momento de preparação de suas aulas.
\end{abstract}

Palavras-chave: Formação de professores; Conhecimento matemático para o ensino; Ensino de álgebra; Equação.

\section{Knowledge mobilized by teachers to plan classes on equations}

\begin{abstract}
Based on the results of research on teacher education, the present study aimed to investigate and mapping teachers' mathematical knowledge when they think about and they prepare their classes about equation. We take as theoretical framework the results of researches from Ball and her colleagues, in particular, the concepts of "knowledge of content and students" and "knowledge of content and teaching". From a methodological point of view, we have developed a qualitative-interpretive research involving a group of six teachers. Among the results we identified elements of the "knowledge of equation and students", as the difficulty of students to characterize the concept of the equation, as well as elements of the "knowledge of equation and teaching" as the appreciation of the context in the moment to prepare teaching

1 Uma versão preliminar e parcial deste artigo foi apresentada no "60 Seminário Internacional de Pesquisa em Educação Matemática - SIPEM", em novembro de 2015.

2 Doutor em Educação Matemática pela PUC/SP. Professor Adjunto no Centro de Matemática, Computação e Cognição (CMCC) da Universidade Federal do ABC (UFABC). Líder do grupo de pesquisa "FORMATE - Formação Matemática para o Ensino: conhecimento profissional docente e desenvolvimento curricular", certificado pelo CNPq. E-mail: alessandro.ribeiro@ufabc.edu.br.

3 Doutorando em Didática, pela "Faculté des sciences de l'éducation" da "Université de Montréal". Mestre em Ensino, História e Filosofia das Ciências e da Matemática, pela UFABC. Licenciado em Matemática, bem como Bacharel em Ciência e Tecnologia, também pela UFABC. E-mail: faugusto@ufabc.edu.br .
\end{abstract}


activities of the equation. This study ratifies the relevance of investigating teachers involved in their own practice, particularly at the moment of preparation of their classes.

Key words: Teacher education; Mathematical knowledge for teaching; Teaching of algebra; Equation.

\section{Introdução: problematizando o foco de pesquisa}

Equação é um dos conceitos mais importantes que permeiam a Matemática. As equações são utilizadas na Aritmética, na Álgebra, na Geometria, etc. Porém, não apenas na Matemática: as equações também são importantes em diversas áreas das Ciências, em que existem inúmeras aplicações, como, por exemplo, na Física, na Química, na Biologia, na Economia, nas Engenharias etc. A importância das equações extrapola os muros da academia, uma vez que são muito utilizadas no cotidiano, em diferentes níveis educacionais, e, geralmente, começam a ser estudadas no Ensino Fundamental, como ocorre no Brasil (Brasil, 1997) e nos Estados Unidos da América (National Council of Teachers of Mathematics [NCTM], 2000).

Por um lado, existem pesquisas que evidenciam as dificuldades dos alunos da educação básica referentes a conceitos matemáticos, em especial, ao conceito de equação (Dreyfus \& Hoch, 2004; Stephens \& Ribeiro, 2012; Xu, Stephens \& Zhang, 2012). Porém, tais dificuldades não estão restritas aos alunos, pois elas também têm sido identificadas entre os professores da educação básica (Attorps, 2003; Doerr, 2004). A literatura nos aponta algumas lacunas na formação do professor de Matemática para a educação básica (Benayad, 2012; Charalambous, 2008; Figueiredo, 2007), as quais, muitas vezes, podem contribuir de forma negativa ou limitadora na compreensão que os estudantes constroem acerca de conceitos algébricos e, mais ainda, podem repercutir diretamente no ensino realizado por tais professores. Ensinar, de maneira geral, é um ato complexo, o qual envolve muitos aspectos/domínios que devem ser mobilizados por aqueles que o praticam. O ensino de Matemática está inserido nessa problemática, e a formação do professor deve considerar uma gama ampla e variada de conhecimentos profissionais que contribuam para a aprendizagem dos alunos (Ball, Thames \& Phelps, 2008; Shulman, 1986, 1987).

Dessa maneira, pareceu-nos relevante, como estratégia de pesquisa, investigar e mapear quais conhecimentos matemáticos os professores e futuros professores julgam importantes ao ensino, sobretudo quando preparam aulas sobre equações para a Educação Básica. Entendemos que a mobilização de tais conhecimentos, de forma eficaz para o ensino, pode contribuir para ampliar a compreensão desse conhecimento matemático, bem como a compreensão dos alunos e de seus desempenhos escolares. Utilizamos, nesta investigação, o modelo teórico do Conhecimento Matemático para o Ensino - doravante CME -, que corresponde ao Mathematical 
Knowledge for Teaching (Ball et al., 2008). O CME é composto por seis subdomínios distintos, os quais serão apresentados na próxima seção.

Considerando as restrições de tempo e de espaço inerentes a qualquer trabalho acadêmico, pretendemos discutir, neste artigo, alguns resultados da pesquisa de mestrado de Oliveira (2014). Nosso foco, então, incidira sobre dois desses subdomínios, a saber: conhecimento do conteúdo e dos estudantes; conhecimento do conteúdo e do ensino. Os dados a serem analisados, neste trabalho, foram produzidos com os professores que participaram dessa pesquisa, e coletados por meio de entrevistas, questionários e dinâmicas de grupo.

\section{O ensino de Álgebra e o Conhecimento Matemático para o Ensino: revisão de literatura}

$\mathrm{Xu}$ et al. (2012) identificam nos resultados de sua pesquisa que os alunos chineses de 5ㅇ, 6 e 7o anos do Ensino Fundamental geralmente apresentam dificuldades na transição aritmética, envolvendo sentenças e operações numéricas típicas dos anos iniciais de escolarização, para a aprendizagem de álgebra. Dificuldades semelhantes foram observadas por Stephens e Ribeiro (2012), no que se refere aos pensamentos relacional e computacional de alunos do Ensino Fundamental II. Estes pesquisadores observaram, por exemplo, que alunos dos $7^{\circ}$ e $8^{\circ}$ anos, em sua maioria, resolvem questões envolvendo as quatro operações e conceitos, como o sinal de igualdade, apenas por métodos computacionais, apresentando lacunas na construção do pensamento relacional, nestas situações. Dreyfus e Hoch (2004), ao realizar uma investigação com alunos de faixa etária equivalente à dos estudantes do Ensino Médio brasileiro, detectaram que tais alunos não reconheceram a estrutura interna de uma equação e, além disso, esses alunos têm a percepção de equação como somente um processo de resolução, isto é, uma conta a ser resolvida. Ribeiro (2001), no Brasil, detectou que os alunos, na busca de soluções para situações problema que envolvem conceitos elementares de Álgebra, utilizam-se de técnicas e procedimentos mecânicos.

Apresentadas algumas dificuldades de estudantes na educação básica no que se refere à aprendizagem de equações, cabe, então, conhecer o que as pesquisas apontam acerca da formação e do conhecimento dos professores quando se trata do outro lado da moeda, isto é, da parte de quem ensina equações. Corroborando a ideia da necessidade de pesquisar o ambiente escolar, mas com o foco na formação de professores, Figueiredo (2007) afirma haver, no cenário brasileiro, ainda,

uma carência tanto sobre a formação inicial como sobre a do formador de professores que ensinarão Matemática, o que impede que se possam 
perceber os saberes, habilidades e competências que estes mobilizam ao lidarem com conhecimentos de sua área específica, a Educação Matemática (p. 22).

Assim como a pesquisadora aqui referida, outros autores corroboram a necessidade de um atento olhar à formação e às dificuldades enfrentadas pelos docentes no seu ambiente laboral. Benayad (2012) descreve que "trabalhar como professor não é fácil, requer um arsenal de conhecimento teórico e prático. Para isso, precisamos de uma formação adequada e suficiente" (p. 1479 [tradução nossa]). Ao pensar na formação de professores, associada à Álgebra, notamos, na pesquisa de Attorps (2003), que os dez professores por ela investigados declararam ensinar equações com foco em procedimentos e métodos, e não na busca de compreensão de significados de tais equações. Existe uma correlação positiva entre o desempenho do aluno e o conhecimento do professor, isto é, quanto maior for o conhecimento do professor, melhor desempenho será esperado do aluno no processo de ensino e de aprendizagem (Charalambous, 2008). Benayad (2012) aponta para a necessidade de uma agenda de pesquisa associada à forma como se relaciona o conhecimento do professor com sua abordagem de instrução:

Essencialmente, a análise das necessidades [para a formação docente] permite descrever e documentar o problema, a necessidade, para melhorar a situação, para estabelecer ligações com as questões da organização, definindo os objetivos da formação, indicadores para medi-la, e considerar as condições ideais para a transferência para o meio de trabalho. (p. 1482 [tradução nossa]).

Por um lado, existem avaliações externas que demonstram baixo rendimento matemático dos alunos na educação básica (PISA, SARESP, ENEM) e, dessa maneira, corroboram as pesquisas supracitadas, que apontam diversas dificuldades desses alunos em conteúdos matemáticos, tais como álgebra, equação, entre outros. Por outro lado, algumas pesquisas apontam que a formação de professores está aquém do que deveria ser, inclusive com insatisfações dos licenciandos, que têm grande potencial para se tornarem docentes. Essa dificuldade, apontada pelas pesquisas, abrange inúmeras áreas das ciências, inclusive a Matemática. Por fim, também existem estudos que sugerem uma agenda de pesquisa associada à investigação dos conhecimentos dos futuros professores com a melhoria das instruções e das práticas desses professores.

Estes estudos nos motivaram a projetar uma pesquisa, tendo algumas questões norteadoras para seu desenvolvimento: Como os conhecimentos mobilizados pelos professores, ao prepararem suas aulas sobre equação para a educação básica, levam 
em conta as dificuldades apresentadas por seus estudantes? Além desta, outro questionamento nos pareceu relevante: Quais as diferentes abordagens, recursos, estratégias de ensino, que visem à superação das dificuldades dos estudantes, os professores da educação básica julgam importantes utilizar, quando esses estão preparando suas aulas sobre equação?

Essas questões parecem ratificar algumas necessidades apontadas por investigadores da área de formação de professores bem como consideram questões voltadas às práticas dos professores, em especial, para os conteúdos algébricos como é o caso de equações (Doerr, 2004).

Nesse contexto, ganham importância os estudos de Ball et al. (2008) acerca dos domínios do Conhecimento Matemático para o Ensino (CME), isto é, do "conhecimento matemático utilizado para realizar o trabalho de ensinar Matemática” (Hill, Rowan \& Ball, 2005, p. 373 [tradução nossa]).

O CME possui seis subdomínios, conforme apresentado no esquema seguinte. Mas, como o objetivo deste artigo é discutir o "conhecimento do conteúdo e dos estudantes" e o "conhecimento do conteúdo e do ensino" (Ball et al., 2008) que os professores da educação básica mobilizam quando estão preparando suas aulas sobre equações, passamos a explorar tais conceitos a seguir.

Figura 1: Domínios do Conhecimento Matemático para o Ensino.

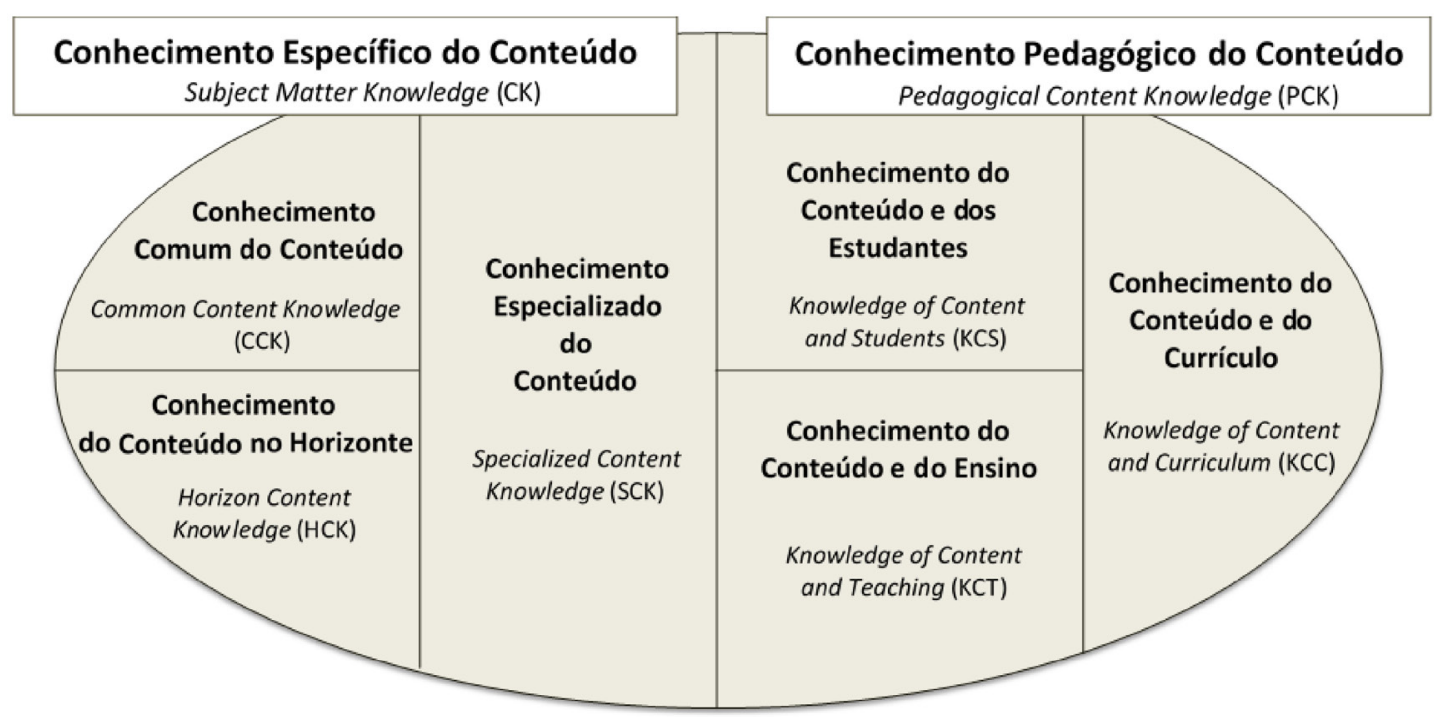

Fonte: Adaptado de Ball, Thames e Phelps (2008, p. 403)

Segundo Ball et al. (2008), entende-se "conhecimento do conteúdo e dos estudantes" como uma combinação entre o conhecimento matemático e o conhecimento sobre os estudantes em relação a tal conhecimento matemático em questão. O do- 
cente necessita ter familiaridade com os alunos, no que tange a uma compreensão matemática específica dos conteúdos que estão em jogo. Assim, por meio desses, é possível que o professor consiga identificar antecipadamente as principais dificuldades dos alunos sobre aquele determinado conceito, para então sugerir alguns exemplos ou representações que possam facilitar sua aprendizagem. Portanto, o docente deve ser capaz de ouvir e interpretar os raciocínios incompletos e emergentes dos alunos, na linguagem deles.

Ainda, segundo os mesmos autores, por "conhecimento do conteúdo e do ensino" entende-se uma combinação entre o conhecimento matemático e o conhecimento sobre o ensino dos conteúdos matemáticos em questão. $\mathrm{O}$ docente deve ser capaz de utilizar uma determinada representação, ao ensinar um conceito específico, e identificar diferentes métodos e procedimentos relacionados àquela ideia. Logo, é uma interação entre a compreensão matemática específica e a compreensão de questões pedagógicas associadas à aprendizagem dos alunos sobre/de um determinado conceito matemático.

É importante notar que, nos subdomínios acima, a expressão “combinação” não está associada apenas a ter conhecimentos sobre a Matemática e sobre os estudantes ou sobre o ensino separadamente, mas também a compreender o conhecimento do conteúdo matemático e sua relação, suas implicações, suas íntimas relações com os estudantes e com o seu ensino.

\section{Do contexto investigado ao desenho da pesquisa}

Nossa investigação foi desenvolvida sob uma perspectiva qualitativa, com um enfoque teórico interpretativo (Bogdan \& Biklen, 1994; Creswell, 2010; Lüdke \& André, 1986). Os participantes da pesquisa possuíam experiência nos ensinos Fundamental e Médio, os quais estavam envolvidos em processos de formação inicial ou de formação continuada, tendo sido selecionados por meio de convites pessoais.

Isto posto, destacamos que nossas análises tomam por base os dados produzidos por seis professores que participaram do presente estudo. A seguir, apresentamos algumas de suas características, esclarecendo que, na transcrição dos dados, os participantes, para preservar seu anonimato, receberam nomes fictícios (Quadro 01) e o pesquisador foi identificado como "Mestre dos Magos". 
Quadro 01: Caracterização dos professores à época da coleta dos dados

\begin{tabular}{|l|l|}
\hline Nome & Características dos professores considerados à época da coleta dos dados. \\
\hline Bobby & $\begin{array}{l}\text { Estava cursando a pós-graduação stricto sensu, tinha três anos de experiência } \\
\text { de docência na educação básica, inclusive com aulas particulares, e estava } \\
\text { ministrando aulas para o 6o e o 7o anos do Ensino Fundamental. }\end{array}$ \\
\hline Diana & $\begin{array}{l}\text { Estava cursando a graduação, tinha dois anos de experiência de docência na } \\
\text { educação básica, inclusive com aulas particulares, e estava ministrando aulas } \\
\text { para o 1o e o 3o anos do Ensino Médio. }\end{array}$ \\
\hline Eric & $\begin{array}{l}\text { Estava cursando a graduação, tinha dois anos e meio de experiência de docên- } \\
\text { cia na educação básica, inclusive com aulas particulares, e estava ministrando } \\
\text { aulas para todos os anos do Ensino Médio. }\end{array}$ \\
\hline Presto & $\begin{array}{l}\text { Cursou uma pós-graduação lato sensu, tinha nove anos e meio de experiência } \\
\text { de docência na educação básica, e estava ministrando aulas para o 4o, o 6o e o } \\
\text { 8o anos do Ensino Fundamental e para o 10 ano do Ensino Médio. }\end{array}$ \\
\hline $\begin{array}{l}\text { Estava cursando uma pós-graduação lato sensu, tinha cinco anos e meio de } \\
\text { experiência de docência na educação básica, e estava ministrando aulas para o } \\
\text { 8o e o 9o anos do Ensino Fundamental e para todos os anos do Ensino Médio. }\end{array}$ \\
\hline Sheila & $\begin{array}{l}\text { Estava cursando uma pós-graduação stricto sensu, tinha três anos de experiên- } \\
\text { cia de docência na educação básica, inclusive com aulas particulares, e estava } \\
\text { ministrando aulas para o 6o e o 7o anos do Ensino Fundamental e para um curso } \\
\text { pré-vestibular, além de ministrar aulas para a Educação de Jovens e Adultos. }\end{array}$ \\
\hline
\end{tabular}

Fonte: Oliveira (2014, p. 57-58)

Para atender ao objetivo de investigar e mapear quais os conhecimentos matemáticos que os professores e futuros professores mobilizam ao pensar e preparar uma aula sobre o conceito de equação para a Educação Básica, utilizamos os dados obtidos em duas etapas de nossa pesquisa. Além disso, cabe destacar que a opção por explorar, na análise, os dois subdomínios, deve-se ao fato de que, nessas duas etapas, foram produzidos mais dados referentes a esses subdomínios.

A primeira etapa foi composta por um questionário que objetivou (i) identificar aspectos da formação acadêmica e profissional dos professores participantes; (ii) identificar os possíveis tipos de conhecimentos (Ball et al., 2008) que os professores poderiam mobilizar.

Os questionários foram divididos em 4 partes e continham 17 questões. As questões da primeira parte versavam sobre a formação acadêmica e profissional, enquanto as questões da segunda parte buscavam investigar o conhecimento sobre e/ou a utilização de documentos curriculares oficiais. De maneira mais geral, procuramos, nesta etapa, abordar a forma como os professores preparam aulas: se utilizam, ou não, livros e outros materiais didáticos para preparar as aulas.

Na terceira parte do questionário, decidimos explorar as questões mais relacionadas ao conceito de equação, ou seja, sobre como os professores pensavam e 
preparavam aulas para o ensino de equação na Educação Básica. Por fim, na quarta e última parte do questionário, os professores foram solicitados a identificar, entre 14 sentenças matemáticas apresentadas por nós, quais delas classificariam como sendo equações.

Como exemplo de tais sentenças, temos: "a) $3 x^{2}+7 x+9$; b) $3 \sqrt{x}-15=3$; c) $\log (x) \geq 3 x+8$; d) $\operatorname{sen}^{2}(y)+\cos ^{2}(y)=1$ " (Oliveira, 2014, p. 158). Cabe destacar que, desses exemplos, somente a segunda sentença se caracteriza como uma equação, mesmo que a potência da variável $x$ seja igual a $1 / 2$, uma vez que na primeira sentença há ausência da igualdade, na terceira sentença a presença do sinal de comparação, e a quarta sentença é uma identidade.

Solicitamos ainda aos professores, nessa última etapa, que explicitassem os critérios utilizados para caracterizar como equação determinada sentença matemática. Além disso, solicitamos que refletissem sobre a tarefa: "Seus alunos conseguiriam identificar as mesmas situações matemáticas como sendo equações? Eles (os alunos) conseguiriam justificar corretamente quais das sentenças eram equações?"

Ao final dessa fase, a qual foi respondida individualmente, foi solicitado aos professores que trouxessem materiais que julgassem importantes para preparar uma aula sobre equações. Não restringimos, nem indicamos para qual ano tal aula seria preparada, já que gostaríamos de investigar se os professores fazem tal associação, a qual entendemos como sendo parte do conhecimento (Ball et al., 2008) que o professor poderia mobilizar.

A segunda etapa da coleta de dados contemplou a observação participante, no momento em que os sujeitos elaboraram, em duplas, uma aula sobre equações. Foram apresentados e explicados sucintamente aos professores os objetivos do encontro e, em seguida, foi entregue um roteiro de recomendações, cuja utilização era opcional, que poderia auxiliá-los na preparação de suas aulas.

O referido roteiro visava incentivá-los a discutir ordenadamente a preparação da aula, focando na mobilização dos conhecimentos sobre equações na perspectiva de Ball et al. (2008), uma vez que, ao analisar os dados da primeira etapa da pesquisa, percebemos que os professores optaram por sintetizar demasiadamente suas respostas. Entendemos como um fator positivo os roteiros por nós elaborados, à medida que tinham como propósito estimular o professor a pensar, de maneira sistematizada, sobre seu plano de aula (Libâneo, 1993). Tal roteiro abordou desde questões organizacionais mais amplas sobre a aula preparada, até questões voltadas aos conteúdos específicos relacionados às equações.

Os encontros, nessa segunda etapa da coleta de dados, possibilitaram tempo suficiente para que os professores completassem a preparação de suas aulas e estes 
foram registrados por meio de gravações em áudio. Em média, foram dois encontros, com duração de três horas cada, e os professores trabalharam em duplas.

Por fim, é importante destacar que a codificação dos dados já havia sido preestabelecida, uma vez que o referencial teórico utilizado nesta pesquisa, o CME, somado aos objetivos, já nos sugeriam tais unidades de análise - os subdomínios dos conhecimentos, como apontados por Ball et al. (2008). Para mais detalhes sobre a metodologia e acesso aos instrumentos de coleta de dados utilizados na pesquisa que originou este artigo, convidamos os leitores a consultar a dissertação de Oliveira (2014).

\section{Produção dos dados e análises}

Tendo por base o marco teórico definido pelo CME e seus diferentes subdomínios (Ball et al, 2008), nas análises, a seguir, são discutidos e analisados os dados produzidos nesta pesquisa, no que se refere, em particular para este artigo, aos subdomínios "conhecimento de equação e dos estudantes" e "conhecimento de equação e do ensino". Vale destacar que, daqui em diante, toda vez que nos referirmos a estes subdomínios, fazendo referência ao conceito matemático de equação, utilizaremos estes dois subdomínios sem fazer referência, de maneira explícita, ao trabalho de Ball e seus colaboradores. Além disso, cabe também observar que estes autores não definem tais subdomínios em relação ao conceito de equação. Essa vinculação somos nós que fazemos neste trabalho.

Considerando o subdomínio referente aos conhecimentos de equação e do ensino, quando questionamos os professores para saber se eles utilizam outros materiais didáticos ao prepararem suas aulas, cabe destacar o depoimento das professoras Diana e Sheila.

Figura 02: Protocolo do questionário da professora Diana ${ }^{4}$.

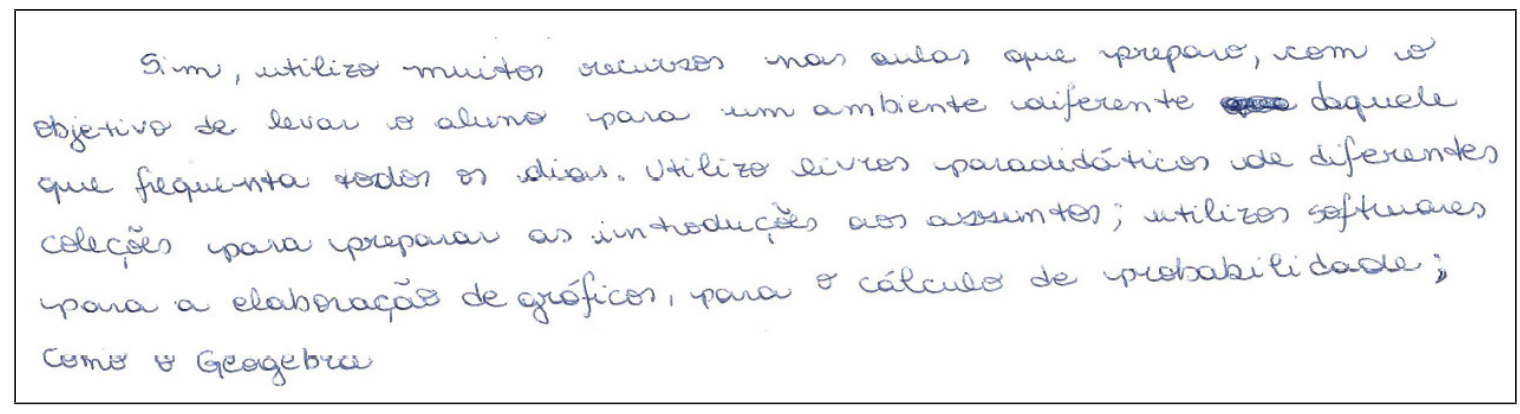

Fonte: Oliveira $(2014$, p.75)

4 Transcrição do Protocolo: "Sim, utilizo muitos recursos nas aulas que preparo, com o objetivo de levar o aluno para um ambiente diferente daquele que frequenta todos os dias. Utilizo livros paradidáticos de diferentes coleções para preparar as introduções aos assuntos; utilizos (sic) softwares para a elaboração de gráficos, para o cálculo de probabilidade; como o Geogebra”. 
Figura 03: Protocolo do questionário da professora Sheila 5 .

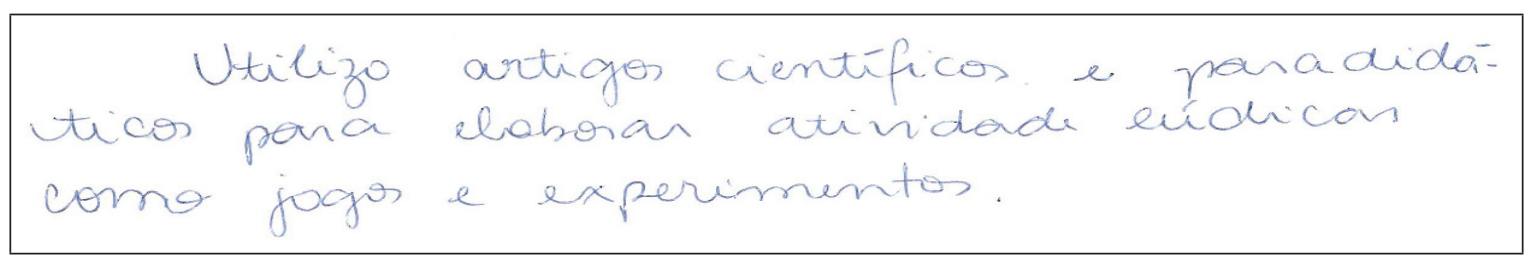

Fonte: Oliveira (2014, p.75)

Os depoimentos de Diane e Sheila evidenciam que, ao preparar suas aulas sobre equações, não se limitam apenas à utilização de livros didáticos. Utilizam também materiais paradidáticos, softwares, jogos e experimentos, evidenciando um conhecimento curricular diversificado da matemática.

Ao serem questionados sobre como introduzem o conceito de equação, assim se pronunciaram:

Figura 04: Protocolo do professor Eric ${ }^{6}$.

Gosto de discutir e uma questáo que sempre surge plinicio
desta apestáo é a etmologia da poloura equacior, igualdade.

Fonte: Oliveira (2014, p.77)

Figura 05: Protocolo do professor Hank ${ }^{7}$.

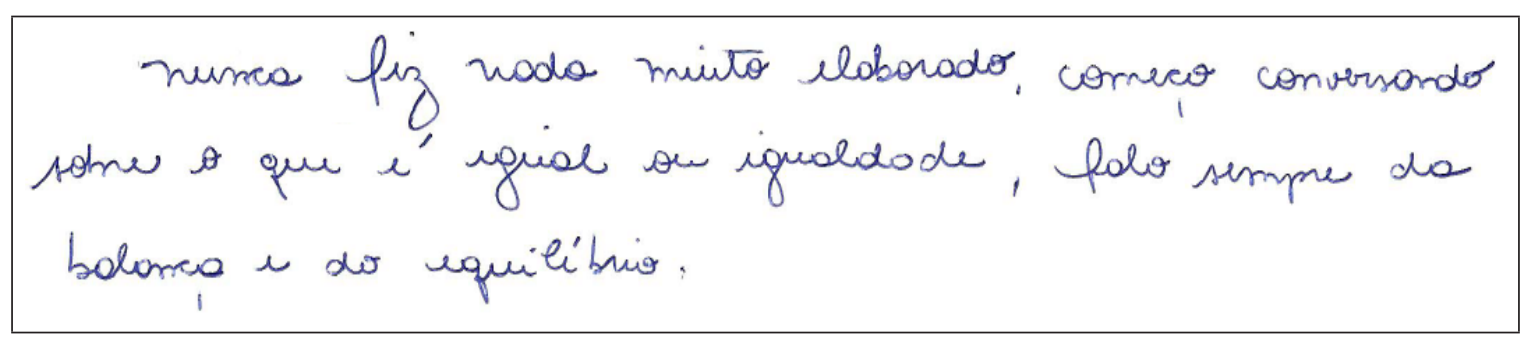

Fonte: Oliveira (2014, p.77)

Os professores Eric e Hank destacam que costumam introduzir o estudo de equações explorando o significado etimológico das palavras "equação" e "igualdade" e a utilização de modelos analógicos como a balança e seu equilíbrio. Ou seja, es-

5 Transcrição do Protocolo: "Utilizo artigos científicos e paradidáticos para elaborar atividade (sic) lúdicas como jogos e experimentos".

6 Transcrição do Protocolo: "Gosto de discutir e uma questão que sempre surge para [o] início desta questão é a etmologia (sic) da palavra equação, igualdade”.

7 Transcrição do Protocolo: "Nunca fiz nada muito elaborado, começo conversando sobre o que é igual ou igualdade, falo sempre da balança e do equilíbrio". 
ses professores preocupam-se em mobilizar elementos semânticos do subdomínio conhecimento de equação e do ensino. Além disso, ao preparar a aula, o docente Hank confirma que já utilizou a analogia do sinal de igualdade com uma balança, bem como reconheceu a importância do ensino do conceito de equação em anos posteriores do ensino, como podemos ver no excerto da Figura 06:

Figura 06: Excerto do diálogo entre Hank e mestre do magos sobre ensino de resolução de equações.

\begin{abstract}
Mestre dos Magos: Você acha que isso é interessante eles... de vocês, professores, ensinarem os alunos a pensarem na hora de...

Hank: Sim. Inclusive, quando é abordada [o tema sobre] equação, lá na sexta série, inclusive é até consenso com os professores da escola de falar: "Pelo amor de Deus, não ensina passa para um lado vira menos, passa para outro vira mais, passa para o outro lado multiplicando", porque eles [alunos] não entendem, né, o porquê daquilo. Só que, em contrapartida, uma vez eu fiz um teste, fiz com as crianças, quando entrei nesse assunto de ensinar a balança, porque você soma dos dois lados, então, um é eliminado, o outro fica. Porque você subtrai dos dois lados e sempre fazendo [as operações] igual para não desequilibrar. Aí eles ficam [sem entender muito bem], né, aí você mostra toda a situação. Aí depois que eles já estão [acostumados com essa ideia], daí você diz: "Tem um método mais rápido para chegar nisso, você passa para um lado", [e os alunos respondem] "Ah, por que não ensinou isso antes?”, não interessa [aos alunos saber todos os procedimentos], o que [os] interessa é resolver.

Mestre dos Magos: Aham.

Hank: Mas não o que [operações] está envolvido ali, o porquê daquilo, não interessa para eles o porquê.

Mestre dos Magos: Então, o interesse dos alunos é chegar...

Hank: Chegar ao resultado.

Mestre dos Magos: Chegar ao resultado.

Hank: Só que isso [falta de compreensão correta das operações] fará falta para ele lá na frente. Porque vai chegar numa situação: "Nossa, como chego ao resultado disto?". Ele não consegue reconhecer.
\end{abstract}

Fonte: Oliveira (2014, pp.99-100)

A dupla Sheila e Bobby, por outro lado, parecem apontar (Figura 7) o uso do livro didático como principal recurso para o ensino de equações, pois condicionam o uso da balança de dois pratos, usado em feira, à sua presença física na escola. Ou seja, não levantaram a hipótese de uso desse modelo analógico adaptado ou construído para fins escolares, podendo ser inclusive em forma de desenho de balanças de dois pratos no caderno. 
Figura 07: Excerto do diálogo entre os professores Sheila e Bobby sobre o uso de balança

Sheila: E em relação aos recursos didáticos?

Bobby: Ah, o livro. E uma balança de feira, pois pensamos... É, o livro didático. E se a escola dispuser de uma balança, por exemplo, de frutas...

Sheila: Balança com dois pratos.

Bobby: ...dá até para fazer isso. Mas acho difícil, né!?

Fonte: Oliveira (2014, p.131)

Para complementar as análises, passamos, na sequência, a discutir o subdomínio "conhecimento de equação e dos estudantes". Iniciamos esta parte com um depoimento da professora Diana:

Figura 08: Protocolo da professora Diana sobre a introdução de um tema de estudo em aula ${ }^{8}$.

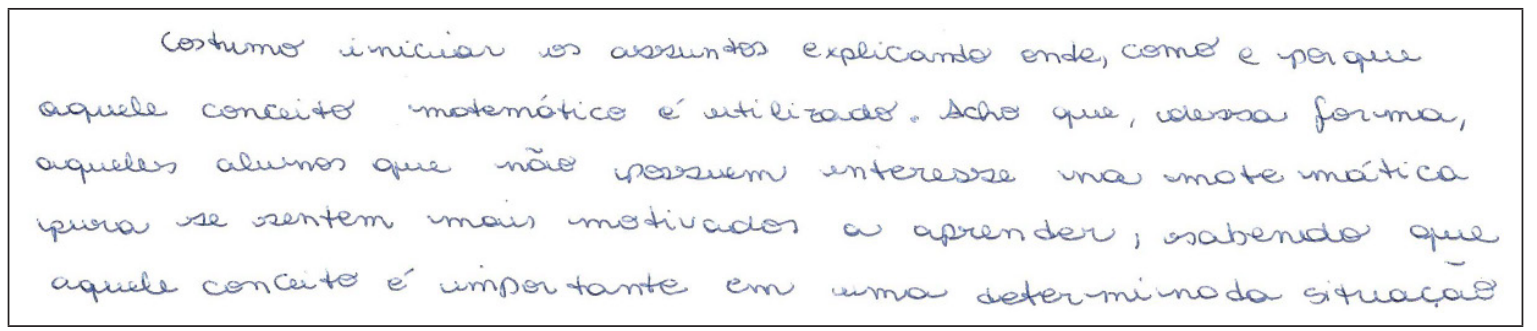

Fonte: Oliveira (2014, p.77)

Neste excerto, Diana afirma que procura abordar ou introduzir um novo conteúdo matemático numa perspectiva de contextualização, cuja finalidade é dar sentido ao aluno à aprendizagem desse conteúdo. Assim, parece-nos que a referida docente mobiliza, nesta situação de preparação - e discussão - de suas aulas, elementos do conhecimento de equação e dos estudantes.

Na mesma perspectiva de análise dos elementos do conhecimento de equação e dos estudantes que os professores mobilizaram, em nossa pesquisa, perguntamos aos docentes, ainda na primeira etapa da coleta de dados, se seus alunos conseguiriam responder e justificar corretamente quais das 14 sentenças matemáticas eram equações. A professora Sheila, por exemplo, afirmou, como podemos ver a seguir, que seus alunos não conseguiriam, pois eles têm dificuldades de compreensão, quando trabalham com a linguagem matemática, principalmente na caracterização ou identificação de uma equação:

8 Transcrição do Protocolo: "Costumo iniciar os assuntos explicando onde, como e por que aquele conceito matemático é utilizado. Acho que, dessa forma, aqueles alunos que não possuem interesse na matemática pura se sentem mais motivados a aprender, sabendo que aquele conceito é importante em uma determinada situação”. 
Figura 09: Protocolo da professora Sheila sobre os possíveis sentidos de equação dos alunos ${ }^{9}$.

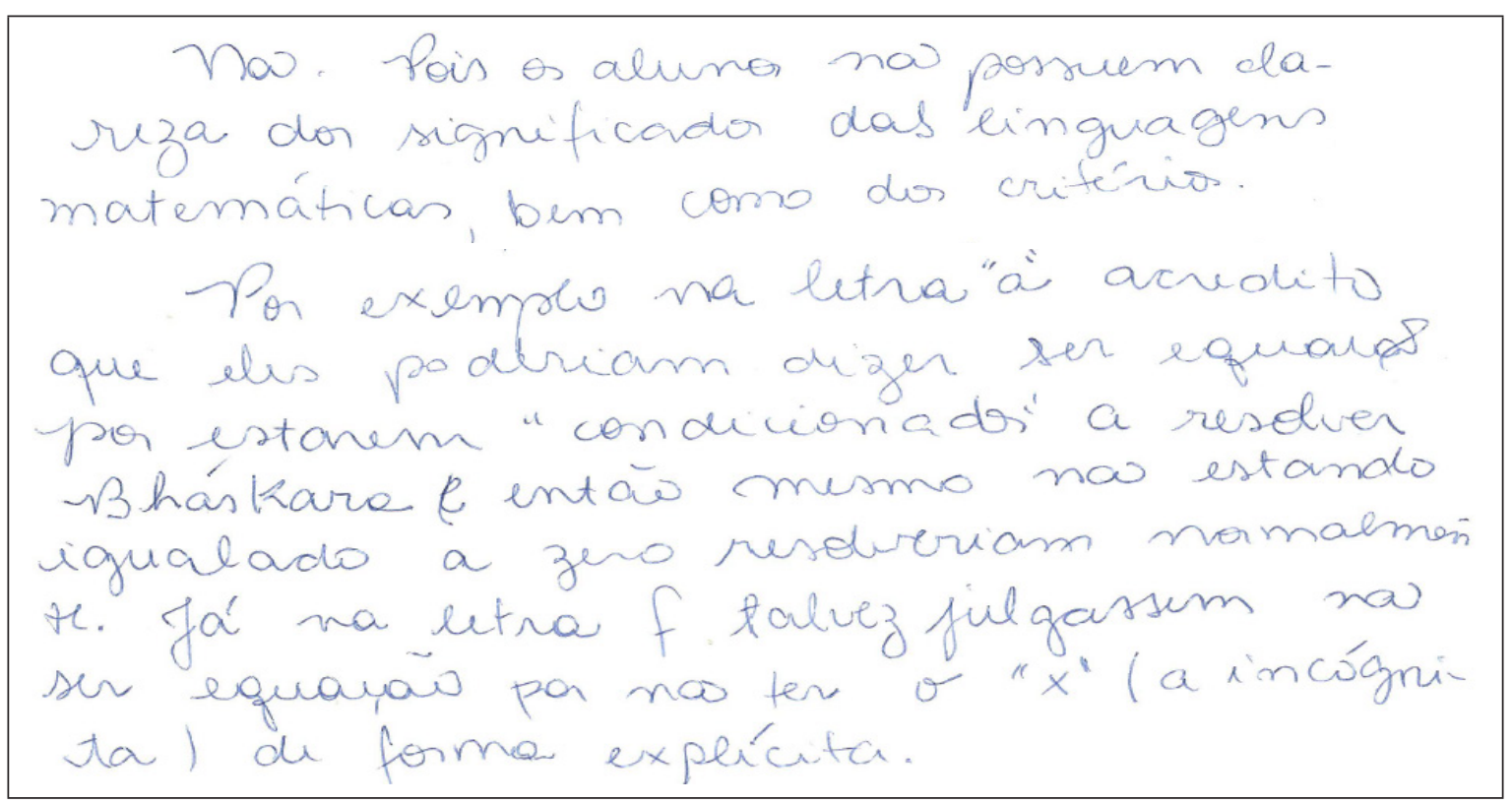

Fonte: Oliveira (2014, p.85)

Na primeira sentença referida por Sheila - “ $3 x^{2}+7 x+9$ ” (letra 'a') - os alunos, segundo ela, poderiam considerá-la como uma equação, ao associá-la à forma de uma equação, cuja resolução se obtém utilizando a fórmula de Bháskara. Observamos aqui uma ratificação das conclusões encontradas por Ribeiro (2001), dentre as quais identificou que os estudantes têm se utilizado de técnicas e procedimentos mecânicos para resolver exercícios algébricos. Além disso, a sentença referida - $15+9=4$. _ (letra 'f') - também seria uma sentença em que os estudantes poderiam encontrar dificuldades, tendo em vista a ausência de incógnita.

Quando estavam discutindo sobre as aulas que estavam preparando, os docentes levantaram a existência de erros e algumas dificuldades dos alunos para reconhecer o significado do símbolo "=" nas sentenças matemáticas. Aqui, neste trecho, pudemos observar novamente a mobilização do conhecimento de equação e dos estudantes.

9 Transcrição do Protocolo: "Não. Pois os alunos não possuem clareza dos significados das linguagens matemáticas, bem como dos critérios. Por exemplo na letra "a" acredito que eles [os alunos] poderiam dizer ser equação por estarem "condicionados" a resolver [pelo método de] Bháskara e então mesmo não estando igualado a zero resolveriam normalmente. Já na letra "f" talvez [os alunos] julgassem não ser equação por não ter o "x" (a incógnita) de forma explícita". 
Figura 10: Excerto do diálogo entre os professores Eric e Hank

Eric: ...quando ele não percebe aquelas passagens, que também, né, todos os algoritmos de somar, passar dividindo, passar multiplicando. Que não é abordado como igualdade, aquilo é abordado como um método, uma prática de passar com o sinal para outro lado. Que nada mais é consequência de uma igualdade.

Hank: Daí quando ele chegar [para resolver] numa potência, ele [estudante] não consegue transformar isso numa raiz, para resolver. Porque ele fica: "O que faço com isso agora?", "Não estou multiplicando, não estou dividindo, não estou somando, não estou subtraindo".

Fonte: Oliveira (2014, p.98)

Como apontam inúmeras pesquisas (Xu et al., 2012; Fiorentini, 2000), um exemplo de erro comum aos estudantes refere-se aos significados que eles atribuem ao sinal "=" numa sentença matemática. Logo, é importante, como ressalta Fiorentini (2005, 2012), que o docente tenha essa consciência e discuta e problematize com outros professores e com seus próprios alunos os diferentes sentidos e significados de símbolos matemáticos que existem e perpassam as diferentes práticas escolares, como é o caso da igualdade.

No intuito de sistematizar alguns resultados que emergiram dos dados e das análises, organizamos o quadro 2, no qual apresentamos relações entre os diferentes subdomínios do CME (Ball et al, 2008) considerados neste artigo e o que "modelamos" por conhecimentos matemáticos para o ensino de equação (CME de equação). Vejamos:

Quadro 2: Síntese dos resultados obtidos e suas respectivas análises.

\begin{tabular}{|c|c|}
\hline Subdomínio do CME & Caracterização dos Conhecimentos sobre Ensino de Equação. \\
\hline $\begin{array}{l}\text { Conhecimento de } \\
\text { equação e do ensino }\end{array}$ & $\begin{array}{l}\text { - Utilizar uma abordagem etimológica das palavras "equação" e } \\
\text { "igualdade", com a finalidade de promover uma maior discussão e } \\
\text { compreensão desse conteúdo em sala de aula. } \\
\text { - Utilizar modelos analógicos como a balança e seu equilíbrio, para } \\
\text { produzir significado aos conteúdos de equação e de igualdade. } \\
\text { - Utilizar artigos científicos para preparar tarefas lúdicas, e cons- } \\
\text { truir e desenvolver estratégias didático-pedagógicas para o ensino } \\
\text { de conteúdos matemáticos. }\end{array}$ \\
\hline $\begin{array}{l}\text { Conhecimento de } \\
\text { equação e dos estu- } \\
\text { dantes }\end{array}$ & $\begin{array}{l}\text { - Conhecer os contextos de significação dos alunos para dar sen- } \\
\text { tido aos conteúdos de equação, principalmente em situações de } \\
\text { resolução de problemas. } \\
\text { - Reconhecer que nem todos os alunos possuem a correta compreen- } \\
\text { são dos significados relacionados às linguagens formais e simbólicas } \\
\text { utilizadas nas equações. } \\
\text { - Aceitar que os alunos têm dificuldades para caracterizar uma } \\
\text { equação, para reconhecer os multissignificados do símbolo "=", } \\
\text { além da realização de operações inversas a fim de isolar a incógnita. }\end{array}$ \\
\hline
\end{tabular}

Fonte: Adaptado de Oliveira (2014, p.150). 


\section{Considerações finais e reflexões para pesquisas futuras}

Neste artigo, fundamentados em dois diferentes subdomínios do Conhecimento Matemático para o Ensino (Ball et al, 2008), apresentamos e discutimos resultados e evidências que nos possibilitaram modelar características do "conhecimento de equação e dos estudantes" e do "conhecimento de equação e do ensino".

Nossas discussões e nossas análises tomaram por base os dados produzidos durante a preparação coletiva de aulas sobre o conceito equação, possibilitando-nos identificar como "conhecimento de equação e dos estudantes" o fato de os professores reconhecerem que os alunos têm dificuldades para caracterizar uma equação, para reconhecer diferentes significados do símbolo “=”, além de realizarem operações inversas a fim de isolar a incógnita quando estão resolvendo uma equação. Além disso, ainda na mesma tipologia de conhecimento, identificamos situações nas quais os professores afirmaram utilizar diferentes contextos - muito semelhantes àqueles vivenciados por seus estudantes - quando estão propondo situações-problemas com a finalidade de mostrar o significado das equações ou a aplicação/utilização das mesmas em contextos cotidianos.

Por outro lado, no que se refere ao "conhecimento de equação e do ensino", pudemos constatar evidências de que os professores utilizam analogias com uma balança e seu equilíbrio em relação aos conteúdos de equação e à caracterização ou ao significado da igualdade, bem como se valem de artigos científicos para preparar tarefas lúdicas e para escolher uma estratégia pedagógica associada a um conteúdo matemático. Além disso, alguns docentes afirmaram utilizar, em sala de aula, uma abordagem etimológica para discutir os múltiplos sentidos e significados dos conceitos e palavras como, por exemplo, "equação" e "igualdade”.

É fato que, como qualquer pesquisa científica, observamos certas limitações no desenvolvimento desta investigação. Reconhecemos que o tempo de duração da coleta de dados pode não ter sido suficiente, haja vista que, possivelmente, com outras etapas de coleta de dados, poderíamos obter mais informações e com maior riqueza de detalhes. Entretanto, reconhecemos que esse fato não põe em xeque os dados e as análises obtidas, uma vez que pudemos identificar alguns tipos dos conhecimentos relacionados ao conceito de equação que foram mobilizados por tais professores.

Ainda assim, gostaríamos de deixar como sugestão de complementação de nosso trabalho a necessidade de observar e analisar, por exemplo, os professores ministrando as aulas que prepararam coletivamente. Nesse novo contexto, certamente, as interações com os estudantes levariam à mobilização de outros significados e conhecimentos acerca do conceito de equação, sejam conhecimentos relacionados aos estudantes, seja aqueles relacionados ao ensino, os quais não foram possíveis de identificar nesta pesquisa.

Por fim, ratificamos nossa crença acerca da importância de desenvolver investigações que versem sobre os diferentes domínios do Conhecimento Matemático 
para o Ensino (Ball et al., 2008) que são mobilizados pelos professores, no que tange a diferentes conceitos matemáticos, tanto para a educação básica quanto para a educação universitária. Em especial, nossa opção foi por investigar um importante momento de sua prática pedagógica: a preparação de suas aulas.

\section{Agradecimentos}

Agradecemos ao Conselho Nacional de Desenvolvimento Científico e Tecnológico $(\mathrm{CNPq})$ pelo auxílio financeiro concedido para a realização desta pesquisa, por meio do Edital CHS 2012. Agradecemos ainda à Universidade Federal do ABC (UFABC), pelas bolsas concedidas a Oliveira, no período em que realizou seu mestrado, assim como à Coordenação de Aperfeiçoamento de Pessoal de Nível Superior (Capes), pela concessão de bolsa de estudos para a realização do doutorado pleno no exterior. Por fim, mas não menos importante, agradecemos aos professores que participaram desta pesquisa.

\section{Referências}

Attorps, I. (2003, February/March). Teachers' Images of the 'Equation' Concept. In CERME 3: Third Conference of the European Society for Research in Mathematics education in Bellaria, Italy. Disponível em http://www.dm.unipi.it/ didattica/CERME3/proceedings/ Groups/TG1/TG1_attorps_cerme3.pdf

Ball, D.L., Thames, M.H., \& Phelps, G. (2008). Content knowledge for teaching: What makes it special? Journal of Teacher Education 59, 389-407.

Benayad, M.A. (2012). Analyse des besoins en formation des enseignants de mathématiques du secondaire. In J.L. Dorier, \& S. Coutat (Eds.), Enseignement des mathématiques et contrat social: enjeux et défis pour le 21 $1^{e}$ siècle - Actes du colloque EMF2012 (SPE1, pp. 1479-1487.

Bogdan, R., \& Biklen, S.K. (1994). Investigação qualitativa em educação: uma introdução à teoria e aos métodos (Maria J. Álvares, Sara B. dos Santos, \& Telmo M. Baptista, trads.). Porto: Porto Editora.

Brasil. (1997). Secretaria de Educação Fundamental. Parâmetros curriculares nacionais: matemática. Brasília, DF: Ministério da Educação.

Charalambous, C.Y. (2008). Mathematical knowledge for teaching and teaching practices: a virtual-design approach to study a complex relationship. In $11^{\text {th }}$ International Congress on Mathematical Education, Topic Study 27: Mathematical knowledge for teaching. Monterrey, México.

Creswell, J.W. (2010). Projeto de pesquisa: métodos qualitativos, quantitativos e misto (3a ed.). Porto Alegre: Artmed, 296 pp.

Doerr, H.M. (2004). Teachers' knowledge and teaching of algebra. In K. Stancey, H. Chick, \& M. Kendal, (Eds.), The future of the teaching and learning of algebra: The $12^{\text {th }}$ ICMI Study (pp. 267-289). New York: Kluwer Academic Publishers. 
Dreyfus, T., \& Hoch, M. (2004). Equations: a structural approach. Proceedings of the 28th Conference of International Group for the PME (pp. 1-152 - 1-155).

Figueiredo, A. (2007). Saberes e concepções de educação algébrica em um curso de licenciatura em Matemática. Tese de Doutorado, Pontifícia Universidade Católica de São Paulo, São Paulo, 290 pp.

Fiorentini, D. (2000). Pesquisando com professores - reflexões sobre o processo de produção e ressignificação dos saberes da profissão docente. In J.F. Matos \& E. Fernandes (Eds). Investigação em Educação Matemática - perspectivas e problemas (pp.187-195). Lisboa: APM.

Fiorentini, D. (2005). A formação matemática e didático-pedagógica nas disciplinas da licenciatura em matemática. Revista em Educação PUC-Campinas, 18, 107-115.

Fiorentini, D. (2012). Formação de professores a partir da vivência e da análise de práticas exploratório-investigativas e problematizadoras de ensinar e aprender matemática. Cuadernos de Investigación y Formación en Educación Matemática, 7 (10), 63-78.

Hill, H.C., Rowan, B., \& Ball, D.L. (2005). Effects of teachers' Mathematica knowledge for teaching on student achievement. American Educational Research Journal, 42(2), 371-406.

Libâneo, J.C. (1993). Organização e gestão escolar: teoria e prática. Goiânia: Alternativa.

Lüdke, M., \& André, M.E.D.A. (1986). Pesquisa em educação: abordagens qualitativas. São Paulo: EPU, 110pp.

National Council of Teachers of Mathematics. (2000). Principles and standards for school mathematics. Reston, VA: National Council of Teachers of Mathematics.

Oliveira, F.A.P.V.S. (2014). Analisando a mobilização de conhecimentos algébricos de profesores de educação básica: o momento de preparação de aulas sobre equações. Dissertação de Mestrado em Ensino, História e Filosofia das Ciências e da Matemática, Universidade Federal do ABC, Santo André, 161ff.

Ribeiro, A. J. (2001). Analisando o desempenho de alunos do Ensino Fundamental em Álgebra, com base em dados do SARESP. Dissertação de Mestrado em Educação Matemática, Pontifícia Universidade Católica de São Paulo, São Paulo, $145 f f$.

Shulman, L. (1986). Those who understand: Knowledge growth in teaching. Educational Researcher 15(2), 4-14.

Shulman, L. (1987). Knowledge and Teaching: Foundations of the New Reform. Harvard Educational Review 57(1), 1-22.

Stephens, M., \& Ribeiro, A. J. (2012). Working towards algebra: the importance of relational thinking. Revista Latinoamerica de Investigación em Matemática Educativa, 15(3), 373-402.

Xu, W., Stephens, M., \& Zhang, Q. (2012). Profiling students' capacities to link Number and Algebra in years 5, 6 and 7 in Nanjing, China. In J. Dindyal, L.P. Cheng, \& S.F. Ng (Eds.), Mathematics educations: Expanding horizons. Proceedings of the $35^{\text {th }}$ annual conference of the Mathematics Education Research Group of Australia, pp.801-808.

Recebido em: 21/11/2015

Aprovado em: 21/12/2015 